\title{
PERANCANGAN JARINGAN VIRTUAL LOCAL AREA NETWORK (VLAN) \& DHCP PADA PT.NAVICOM INDONESIA BEKASI
}

\author{
Taufik Rahman $^{(1)}$, Teguh Rahmat Zaini ${ }^{(2)}$, Giatika Chrisnawati ${ }^{(3)}$ \\ Program Studi Sistem Informasi, Fakultas Teknologi Informasi ${ }^{1,3}$ \\ Universitas Bina Sarana Informatika \\ Program Studi Teknik Informatika, STMIK Nusamandiri ${ }^{2}$ \\ E-mail: taufik@bsi.ac.id, teguhzaini16@gmail.com, giatika.gcw@bsi.ac.id
}

\begin{abstract}
Abstrak
Dalam jaringan berbagi atau sharing adalah suatu hal yang biasa, akan tetapi jika sebalik nya maka ada suatu hal yang harus di konfigurasi ulang, seperti perubahan firewall, perubahan topologi logik dari LAN menjadi virtual local area network. Berubahnya topologi logik menjadikan perubahan pada topologi fisik dan perangkat jaringan pun seperti switch harus mengikuti dari switch unmanage ke switch manageable. Begitupula berubah interface pada routernya. Tujuan penelitian ini adalah untuk meningkatkan keamanan jaringan di PT. Navicom Indonesia menggunakan jaringan VLAN karena terdapat permasalahan dimana setiap divisi dapat saling mengakses data pada komputer yang ada, dan data tidak terpisah dari jaringan. Perancangan jaringan VLAN pada PT. Navicom Indonesia. Dalam perancangan jaringan VLAN ini menggunakan aplikasi Cisco Packet Tracer untuk simulasinya. Kemanan data pada setiap pc akan lebih aman apabila menggunakan jaringan VLAN, karena pada jaringan tersebut kita dapat membuat konfigurasi jaringan mana saja yang saling terhubung. Untuk membuat jaringan VLAN saling berkomunikasi maka diperlukan konfigurasi pada Switch untuk membuat Database VLAN, agar setiap anggota VLAN dapat saling berkomunikasi satu sama lain.
\end{abstract}

Kata Kunci: VLAN, Switch, DHCP

\section{Abstract}

In network sharing or sharing is a common thing, but if the reverse is there is something that must be reconfigured, such as a firewall change, a logical topology change from a LAN to a virtual local area network. Changes in logical topology make changes to the physical topology and network devices such as switches must follow from unmanage switches to manageable switches. Neither changes the interface on the router. The purpose of this study is to improve network security at PT. Navicom Indonesia uses a VLAN network because there are problems where each division can access data on an existing computer, and data is not separate from the network. VLAN network design at PT. Navicom Indonesia. In designing this VLAN network using the Cisco Packet Tracer application for its simulation. Data security on each PC will be safer when using a VLAN network, because on that network we can make any network configuration that is connected to each other. To make a VLAN network communicate with each other, it is necessary to configure the Switch to create a VLAN Database, so that each VLAN member can communicate with each other..

Keywords: VLAN, Switch, DHCP

\section{PENDAHULUAN}

Dalam jaringan berbagi atau sharing adalah suatu hal yang biasa, akan tetapi jika sebalik nya maka ada suatu hal yang harus di konfigurasi ulang, seperti perubahan firewall, perubahan topologi logik dari LAN menjadi virtual local area network. Berubahnya topologi logik menjadikan perubahan pada topologi fisik dan perangkat jaringan pun seperti switch harus mengikuti dari switch unmanage ke switch manageable. Begitupula berubah interface pada routernya.

$$
\text { Penggunaan teknologi jaringan }
$$

komputer sebagai media komunikasi data sampai saat ini semakin berkembang. Kebutuhan atas penggunaan bersama resources yang ada dalam jaringan baik software maupun hardware telah mengakibatkan timbulnya berbagai pengembangan teknologi jaringan itu sendiri. Sejalan dengan tingginya pengguna jaringan yang berharap maksimal terhadap efisiensi kerja bahkan sampai tingkat keamanan jaringan komputer itu sendiri, hal inilah yang membuat berbagai pihak yang bergelut dibidang jaringan berusaha menyempurnakan jaringan itu sendiri (Haqqi \& Badrul, 2016).

Jaringan lokal area berada di organisasi seperti perusahaan, universitas dan sebagainya. 
Dalam beberapa tahun terakhir, dengan perkembangan teknologi, jaringan ini menjadi skala besar dan terdiri dari sejumlah besar perangkat, dan membuat manajemen jaringan ini sulit dalam hal fleksibilitas karena kondisi kendala yang ditempati oleh perangkat dan kurangnya profesional manajemen yang terampil untuk jaringan ini (Rahman, 2018).

Konsep VLAN (Virtual Area Network) banyak keuntungan yang dapat diperoleh dari konsep tersebut, dengan VLAN (Virtual Area Network), memungkinkan kita untuk membuat banyak jaringan komputer (segmentasi) dan mendistribusikan hanya menggunakan saluran distribusi media dan dapat untuk menghubungkan jaringan area lokal (LAN) tanpa mengikuti lokasi geografis(Peniarsih, 2015).

Untuk membangun jaringan interkoneksi Local Area Network (LAN) yang akan diperlukan dalam bentuk grup Virtual Local Area Network (LAN). Alamat IP DHCP yang diberikan oleh router ke PC yang terletak di jaringan. NAT (Network Address Translation) adalah salah satu metode yang digunakan sebagai terjemahan IP untuk mendapatkan masuk ke jaringan yang berbeda. NAT (Terjemahan Alamat Jaringan) dapat memungkinkan host untuk masuk ke jaringan yang berbeda tanpa mengizinkan host yang dimaksudkan untuk memanfaatkan jaringan mereka menggunakan VLAN. Dengan dua jaringan yang berbeda menjadi satu saklar dapat terhubung. Memberikan DHCP IP akan memungkinkan administrator jaringan untuk memberikan alamat $I P$ ke PC untuk $I P$ yang ditugaskan secara otomatis oleh router. Host $I P$ diteruskan dalam jaringan dengan NAT(Natali \& Diansyah, 2016).

Seiring dengan berkembangnya kebutuhan dalam jaringan komputer, diperlukan pengembangan jaringan LAN dalam suatu jaringan komputer. Hal ini tentu saja dapat meningkatkan kebutuhan perangkat switch yang lebih banyak dan akan menambah biaya perancangan. VLAN dapat membagi sebuah LAN menjadi beberapa broadcast domain. Dalam implementasinya VLAN mempunyai keunggulan karena tidak memerlukan perubahan fisik pada jaringan, tetapi dapat memberikan berbagai tambahan pada teknologi jaringan. Untuk dapat melihat kinerja sebuah jaringan komputer, seorang administrator jaringan memerlukan aplikasi
Network Monitoring System untuk simulasi yang dapat mencerminkan arsitektur dari jaringan komputer pada sistem jaringan yang digunakan. Cisco Packet Tracer merupakan software untuk simulasi jaringan komputer yang paling mudah penggunaan dan instalasinya (Fernadi \& Mubarakah, 2015).

Tujuan penelitian ini adalah untuk meningkatkan keamanan jaringan di PT. Navicom Indonesia menggunakan jaringan $V L A N$ karena terdapat permasalahan dimana setiap divisi dapat saling mengakses data pada komputer yang ada, dan data tidak terpisah dari jaringan.

Perancangan jaringan $V L A N$ pada PT. Navicom Indonesia. Dalam perancangan jaringan VLAN ini menggunakan aplikasi Cisco Packet Tracer untuk simulasinya.

\section{BAHAN DAN METODE}

Pada penelitian ini menggunakan Perangkat keras Cisco-1941 sebagai router nya, dan HP-1920 sebagai switch manageable, Sehingga config VLAN dan DHCP dapat dilakukan.

Dalam penelitian menggunakan Network Development Life Cycle (NDLC) adalah metode yang digunakan pada pembuatan atau mendesain infrastruktur jaringan yang dapat memonitoring untuk mengetahui statistik dan performance jaringan (Adinata, 2016), yang digunakan enam tahapan: analisa, desain, simulation prototype, implementasi, monitoring dan manajemen.

\section{A. Analisa Kebutuhan}

Analisa kebutuhan adalah analisa topologi jaringan yang sudah ada pada saat ini dan perencanaan implementasi topologi jaringan virtual local area network dan DHCP yang akan dibuat

\section{B. Desain}

Dari data-data yang didapatkan sebelumnya, tahap design ini akan membuat gambar design topologi jaringan interkoneksi yang akan dibangun, di harapkan dengan gambar ini akan memberikan gambaran seutuhnya dari kebutuhan yang ada. 


\section{Simulation Prototype}

Membuat dalam bentuk simulasi dengan bantuan tools khusus di bidang network seperti BOSON, PACKET TRACER, NETSIM, dan sebagainya, hal ini dimaksudkan untuk melihat kinerja awal dari network yang akan dibangun dan sebagai bahan presentasi dan sharing dengan team work lainnya.

\section{Implementasi}

Tahapan ini akan memakan waktu lebih lama dari tahapan sebelumnya. Dalam implementasi network akan menerapkan semua yang telah direncanakan dan di design sebelumnya.

\section{E. Manajemen}

Manajemen atau pengaturan, salah satu yang menjadi perhatian khusus adalah masalah Policy, kebijakan perlu dibuat untuk membuat / mengatur agar sistem yang telah dibangun dan berjalan dengan baik dapat berlangsung lama dan unsur Reliability terjaga.

\section{HASIL DAN PEMBAHASAN}

\section{A. Jaringan Usulan}

Dalam jaringan usulan ini penulis mengusulkan membuat jaringan VLAN, agar keamanan data yang ada pada PT. Navicom Indonesia Bekasi menjadi lebih baik lagi untuk kedepannya.

\section{B. Topologi Jaringan}

Pada topologi jaringan di PT.Navicom Indonesia Bekasi penulis tetap mengusulkan untuk tetap menggunakan topologi Star, namun tidak lagi menggunakan jaringan LAN melainkan menggunakan jaringan VLAN. Berikut keunggulan jaringan $V L A N$ :

Performance

VLAN mampu mengurangi jumlah data yang dikirim ke tujuan yang tidak perlu. Sehingga lalu lintas data yang terjadi di jaringan tersebut dengan sendirinya akan berkurang.

Mempermudah administrator jaringan setiap kali komputer berpindah tempat maka komputer tersebut harus dikonfigurasi ulang agar mampu berkomunikasi dengan jaringan dimana komputer itu berada. Hal ini membuat komputer tersebut tidak dapat dioperasikan langsung setelah dipindahkan. Jaringan berprinsip VLAN dapat meminimalkan atau bahkan menghapus langkah ini karena pada dasarnya ia tetap berada pada jaringan yang sama.

Mengurangi Biaya

Dengan berpindahnya lokasi, makseperti hal nya diatas, akan menyebabkan biaya instalasi ulang. Dalam jaringan menggunakan VLAN, hal ini dapat di minimalisirkan atau di hapuskan.

\section{Keamanan}

$V L A N$ bisa membatasi pengguna yang bisa mengakses suatu data, sehingga mengurangi kemungkinan terjadinya penyalahgunaan hak akses.

\section{Skema Jaringan}

Pada jaringan usulan penulis di PT.Navicom Indonesia Bekasi yaitu menggunakan topologi star dan skema jaringannya adalah sebagai berikut

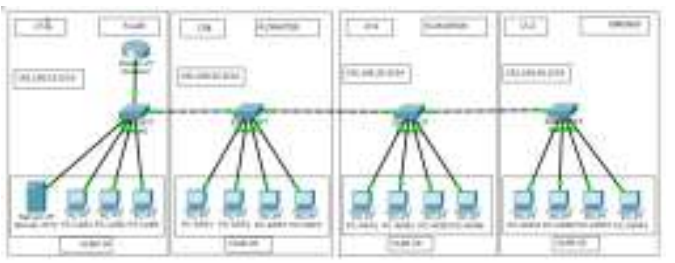

Gambar 1. Skema Jaringan

Pada pembuatan jaringan VLAN ini penulis menggunakan Router sebagai media DHCP Server nya. Penulis mengkonfigurasi Router sehingga dipastikan menghasillkan IP Dinamis yang diberikan pada PC kerja.

\section{Keamanan Jaringan}

Keamanan data dari setiap jaringan dapat dibuat tersendiri, karena segmennya bisa dipisah secara logic. Hal ini akan mengurangi kesempatan data yang akan diganggu atau diusik. VLAN juga akan banyak menciptakan kelompok broadcast sesuai kebutuhan dari jaringan yang dibuat. Jadi jaringan akan dipecah atau dibagi ke dalam jaringan yang lebih kecil sehingga dapat membatasi aksesakses yang tidak di izinkan. Administrator juga akan memiliki kontrol terhadap setiap port dan user yang ada pengaturan keamanan juga dapat dilakukan pada level MAC Address, protokolprotokol atau tergantung kebutuhan itu sendiri 


\section{E. Rancangan Aplikasi}

Rancangan Aplikasi yang diusulkan penulis adalah aplikasi Cisco Packet Tracer di PT. Navicom Indonesia Bekasi. Dengan menggunakan aplikasi ini penulis dapat mensimulasikan tentang jaringan yang akan diterapkan di PT.Navicom Indonesia Bekasi, karena aplikasi ini memiliki banyak pilihan fiturnya untuk mendukung perancangan jaringan VLAN yang akan diimplementasikan pada PT. Navicom Indonesia Bekasi.

\section{F. Manajemen Jaringan}

Topologi Jaringan

Topologi jaringan yang digunakan untuk jaringan usulan pada PT.Navicom Indonesia adalah topologi star. Alasannya karena topologi ini bersifat fleksibel keamanan data yang tinggi, mudah dalam mendeteksi kerusakan pada jaringan jika salah satu komputer mengalami kerusakan, jaringan akan tetap berjalan dan tidak menimbulkan masalah bagi komputer lainnya.

\section{Ip Address}

Ip Address yang digunakan penulis untuk jaringan usulan di PT.Navicom Indonesia Bekasi menggunakan Ip Address kelas C, yaitu pertamanya mempunyai Range 192 sampai 223, dan masing-masing dapat mendukung 254 host.

Tabel 1. Ip Address

\begin{tabular}{|l|l|c|c|}
\hline \multicolumn{1}{|c|}{ Nama } & \multicolumn{1}{|c|}{ Vian } & Ip Address & Gateway \\
\hline Ruang LAB & 10 & 192168.100 .24 & 192.168 .10 .100 \\
\hline Ruang DRAFIER & 20 & 192.108 .20 .024 & 192.108 .20 .100 \\
\hline Raang AKGNIAN & 30 & $192.168 .300 / 24$ & 192.108 .30 .100 \\
\hline Ruang ADMIN & 40 & 192.168 .400 .24 & 192.168 .40 .100 \\
\hline
\end{tabular}

\section{G.Pengujian Jaringan}

Rancangan pengujian yang akan digunakan untuk simulasi jaringan VLAN adalah menggunakan aplikasi Cisco Packet Tracer yang akan diterapkan di PT.Navicom Indonesia Bekasi.

\section{Pengujian Jaringan Awal}

Ini adalah pengujian jaringan yang dilakukan di PT.Navicom Indonesia Bekasi. Saat masih menggunakan LAN. Semua PC bisa saling terhubung satu sama lain sehingga keamanan data sangat rentan untuk disalah gunakan.

A. Tes Ping dari Ruang LAB ke Ruang

Drafter:

Tes Ping dari ruang LAB Ip 192.168.100.5 ke ruang Drafter Ip 192.168.100.8

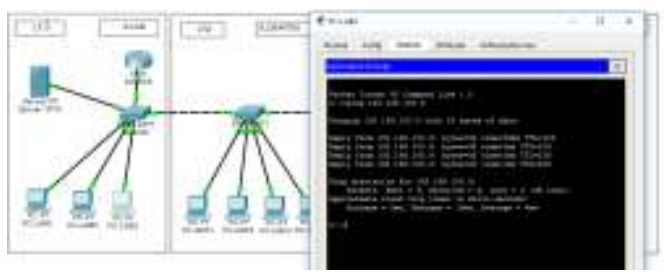

Gambar 2 Tes Ping 1

Pengujian Jaringan Akhir

Ini adalah pengujian jaringan yang penulis sarankan dan dilakukan di PT.Navicom Indonesia Bekasi. Menggunakan aplikasi Cisco Packet Tracer dan penulis mengusulkan jaringan $V L A N$. Karena dari segi keamanan akan menjadi lebih baik lagi dari sebelumnya.

\section{A. Tes Ping antar ruang LAB}

Tes Ping antar VLAN 10 atau sesama anggota jaringan VLAN, Ping dari Pc ruang LAB 1 dengan Ip 192.168.10.4 ke $\mathrm{Pc}$ ruang $\mathrm{LAB} 2$ dengan $I p$ 192.168.10.2

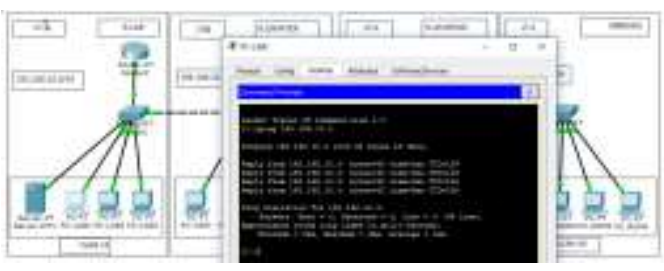

Gambar 3. Tes Ping 2

Tes Ping VLAN 10 ke VLAN 20 atau bukan sesama jaringan VLAN, Ping dari PC ruang LAB dengan Ip 192.168.10.5 ke Pc ruang Drafter Ip 192.168.20.3 


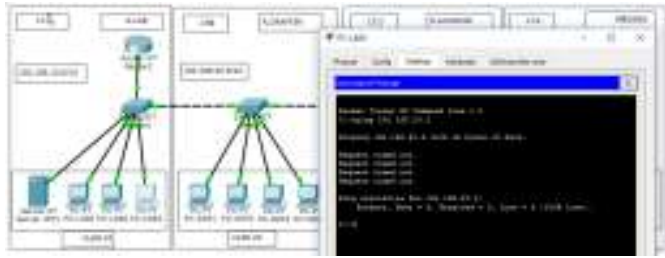

Gambar 4. Tes Ping 3

B. Test Ping antar ruang Drafter

Tes Ping antar VLAN 20 atau sesama anggota jaringan $V L A N$, Ping dari $\mathrm{Pc}$ ruang Drafter 1 dengan Ip 192.168.20.2 ke Pc ruang Drafter 4 dengan $I p$ 192.168.20.5

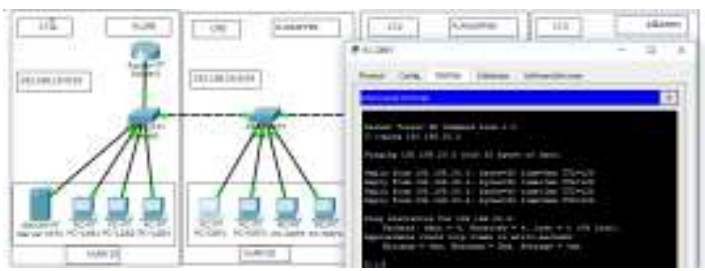

Gambar 5. Tes Ping 4

Tes Ping VLAN 20 ke VLAN 30 atau bukan sesama jaringan VLAN, Ping dari PC ruang Drafter dengan Ip 192.168.20.4 ke Pc ruang Akuntan Ip 192.168.30.3

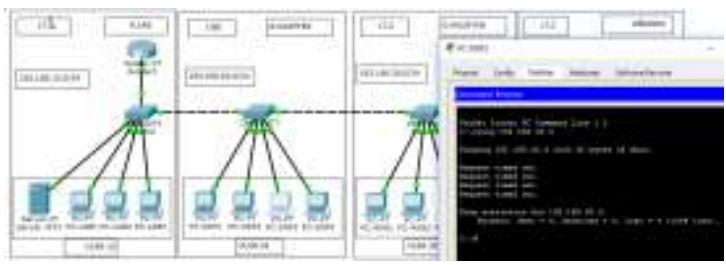

Gambar 6. Test Ping 5

C. Test Ping antar ruang Akuntan

Tes Ping antar VLAN 30 atau sesama anggota jaringan $V L A N$, Ping dari Pc ruang Akuntan 2 dengan Ip 192.168.30.4 ke $\mathrm{Pc}$ ruang Akuntan 4 dengan Ip 192.168.30.2

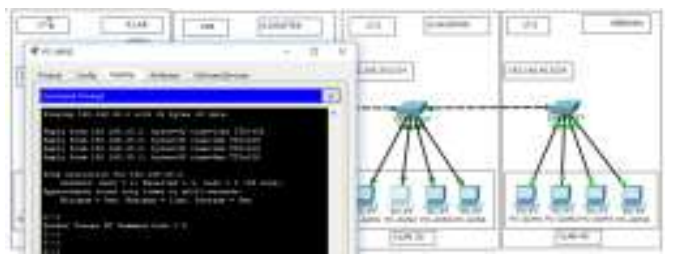

Gambar 7. Test Ping 6

Tes Ping VLAN 30 ke VLAN 40 atau bukan sesama jaringan VLAN, Ping dari
PC ruang Akuntan dengan Ip 192.168.30.3 ke Pc ruang Admin Ip 192.168.40.2

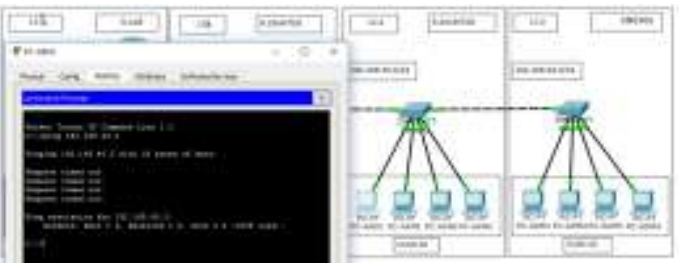

Gambar 8. Test Ping 7

\section{KESIMPULAN}

Kemanan data pada setiap pc akan lebih aman apabila menggunakan jaringan VLAN, karena pada jaringan tersebut kita dapat membuat konfigurasi jaringan mana saja yang saling terhubung. Untuk membuat jaringan VLAN saling berkomunikasi maka diperlukan konfigurasi pada Switch untuk membuat Database VLAN, agar setiap anggota VLAN dapat saling berkomunikasi satu sama lain.

\section{REFRENSI}

Adinata, E. (n.d.). INTERNET MENGGUNAKAN IPCOP PADA PT . INDO BAGUS SLAT. 1-11.

Fernadi, H. S., \& Mubarakah, N. (n.d.). PERANCANGAN VIRTUAL LOCAL AREA NETWORK ( VLAN ) DENGAN DYNAMIC ROUTING MENGGUNAKAN CISCO PACKET TRACER 5 . 33. 110114.

Haqqi, M., \& Badrul, M. (2016). Segmentasi Jaringan Dengan Menggunakan Virtual Local Area Network ( Study Kasus Pt . Jalur Nugraha Ekakurir ). II(2), 7-16.

Natali, J., \& Diansyah, T. M. (2016). Implementasi Static Nat Terhadap Jaringan VLAN Menggunakan Ip Dynamic Host Configuration Protocol (Dhcp). Jurnal Ilmiah Informatika, 1(1), 51-58. Retrieved from http://ejournal.amiki.ac.id/index.php/JIMI/ article/view/10/8 
Peniarsih. (2015). RANCANGAN SISTEM JARINGAN STP (SPANNING TREE PROTOCOL) BERBASIS VLAN. JSI (Jurnal Sistem Informasi), 2(1), 1-10. https://doi.org/https://doi.org/10.35968/jsi. v2i1

Rahman, T. (2018). [PDF] from nusamandiri.ac.id IMPLEMENTASI INTERFACE VIRTUAL LOCAL AREA NETWORK DAN FIREWALL PADA MIKROTIK DAN SWITCH MANAJEMEN. Jurnal Ilmu Pengetahuan Dan Teknologi Komputer, 4(1), 29-36. Retrieved from https://ejournal.nusamandiri.ac.id/index.ph p/jitk/article/download/315/276 